\title{
Minireview
}

nephron

Clinical

Practice

Published online: March 26, 2014

DOI: $\underline{10.1159 / 000358887}$

\section{Update on Rituximab: An Established Treatment for All Immune-Mediated Kidney Diseases?}

\author{
Rhys Evans Alan D. Salama \\ UCL Centre for Nephrology, Royal Free Hospital, London, UK
}

\section{Key Words}

Rituximab -Immune-mediated kidney disease - Systemic lupus erythematosus · Lupus nephritis · Antineutrophil cytoplasm antibody $\cdot$ Idiopathic membranous nephropathy

\begin{abstract}
Rituximab, a monoclonal antibody directed against the CD20 antigen, found on certain B-cell subsets, results in significant B-cell depletion and has been increasingly used in immune-mediated renal disease and transplantation. Although originally applied to what were considered antibody-mediated diseases, it has become clear that auto- and alloreactive $B$ cells contribute in many ways to immune dysfunction, and the benefit of B-cell depletion extends beyond reduction in auto- or alloantibody levels. Most positive data regarding the benefit of rituximab in immune-mediated kidney disease have come from uncontrolled cohort studies, with the only positive controlled clinical trials demonstrating efficacy for the treatment of systemic vasculitis. While negative trials may have potentially missed clinical effects due to trial design, there may be significant differences in responses in different diseases or lack of efficacy due to therapeutic overlap when used with certain drug combinations. Rituximab is a novel treatment that provides a clear alternative for patients in different clinical situations, and allows for
\end{abstract}

customization of therapy. However, much remains to be understood as to how best to use it in a cost-effective manner, when not to use it, and what the long-term impact of therapy may be.

(c) 2014 S. Karger AG, Basel

\section{Introduction}

Rituximab has now become established as an important component of many protocols for the treatment of immune-mediated kidney diseases and antibody-mediated transplant disorders. In this review article we focus on the recent evidence for its benefit, and adverse effects, concentrating on its use in immune-mediated glomerular disease.

Rituximab is a genetically engineered chimeric monoclonal antibody, directed against the CD20 antigen, and contains murine heavy and light chain variable regions with a human IgG1 constant region [1]. CD20 is expressed on the surface of immature and mature B cells, but not on plasma cells, and mediates cellular proliferation and differentiation (fig. 1). Rituximab binds CD20 on the B-cell surface and induces apoptosis or cell lysis through complement-dependent and -independent mechanisms. Thus, administration of rituximab results 


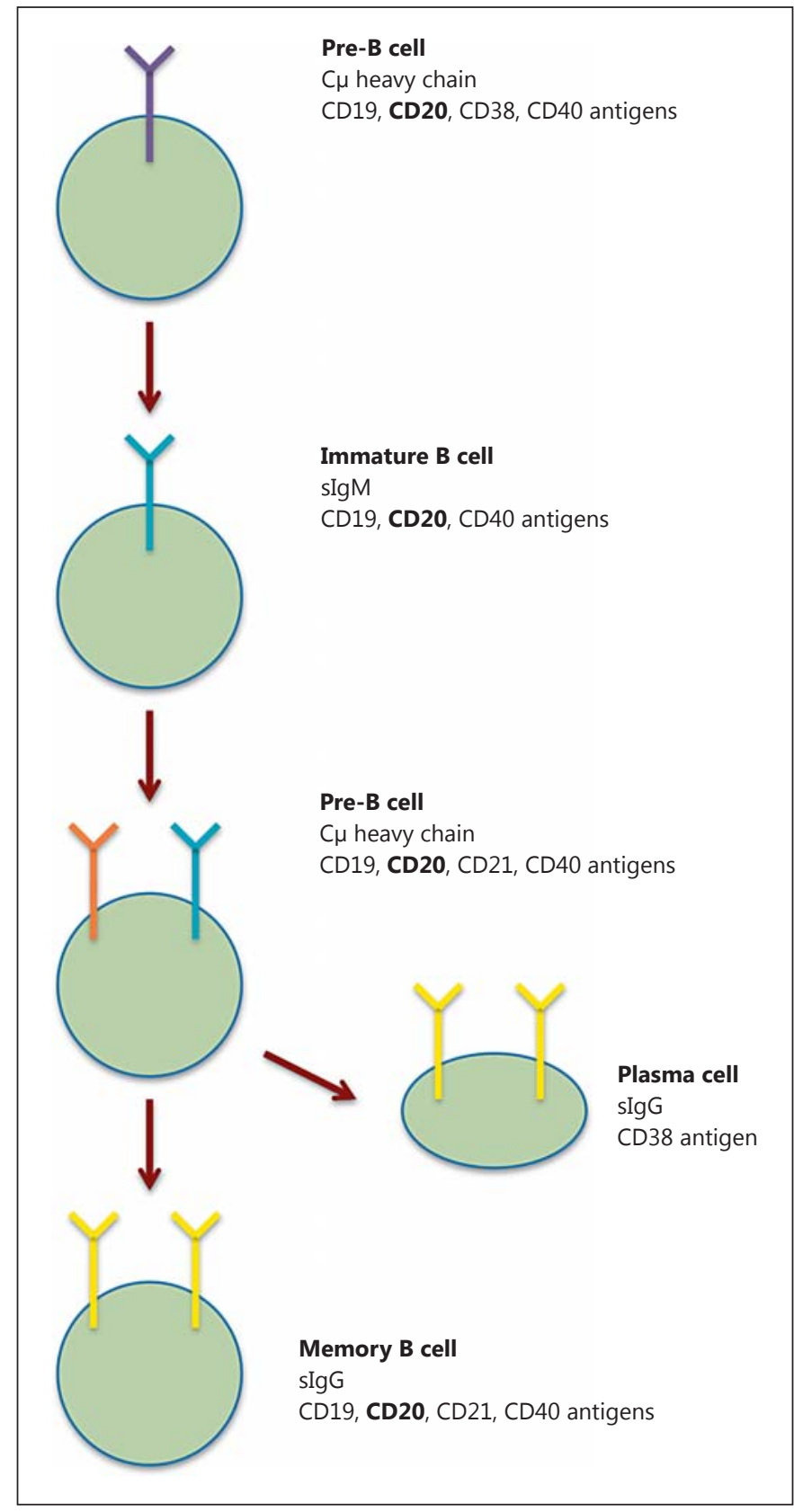

Fig. 1. B-cell development. CD20 is expressed on the surface of immature and mature B cells, and mediates their proliferation and differentiation [adapted from 2].

in rapid depletion of circulating and tissue CD20-expressing B cells which persists for 6-9 months in the majority of patients, although this can be highly variable [2].

Rituximab was first approved in 1997 to treat nonHodgkin's B-cell lymphoma. Since then it has been licensed for use in chronic lymphocytic leukaemia, rheu- matoid arthritis and, more recently, antineutrophil cytoplasmic antibody (ANCA)-associated vasculitis (AAV). In addition, it has increasingly been used off-label to treat a variety of systemic immune-mediated diseases, as well as being an integral part of antibody-mediated transplant rejection and desensitization protocols. In a form of reverse translation, the success following the clinical use of rituximab has highlighted the critical role of $B$ cells in the pathogenesis of various immune-mediated disorders, which had not previously been fully appreciated.

B cells contribute to the (auto)immune response through (i) the processing and presentation of (auto)antigen to $\mathrm{T}$ cells, (ii) the production of cytokines (e.g. TNF- $\alpha$, IL-4 and IL-10), and (iii) their maturation into plasma cells with the production of (auto)antibodies. Rituximab induced depletion of B cells, which correlates with both rituximab levels and the Fc $\gamma$ III a genotype on immune effector cells, interferes with all of these mechanisms [3]. Clinical benefit of rituximab therapy is usually associated with the extent and duration of B-cell depletion; however, depletion of B cells in peripheral blood does not always correlate with tissue depletion, sometimes muddying the relationship between measured Bcell number and clinical effect. Additionally, through alteration in proportions of B-cell subsets, rituximab may augment regulatory $\mathrm{T}$-cell function, reduce NK cell activity, inhibit macrophage activation and following B-cell repopulation promote the return of immunomodulatory transitional B cells.

The optimum dosing regimen for rituximab is unknown. There are two widely used schedules. The first developed for use in lymphoma consists of four weekly intravenous doses of $375 \mathrm{mg} / \mathrm{m}^{2}$, while in treating autoimmune disease, two $1 \mathrm{~g}$ intravenous doses given 2 weeks apart are used. However, neither is used exclusively (the $2 \times 1 \mathrm{~g}$ regimen was used in the main systemic lupus erythematosus (SLE) trials while the $375 \mathrm{mg} / \mathrm{m}^{2}$ regimen was used in AAV trials) and variations of these regimens, including those based on the degree of B-cell depletion, are used in some cohort studies, as outlined below. Further work is really needed to establish what the most cost-efficient and efficacious method of drug delivery is.

\section{Safety and Tolerability}

Over half a million people worldwide have received rituximab therapy during the last 15 years. In the majority of these patients, it appears to be safe and well tolerated [4]. However, common adverse effects include infu- 
sion reactions manifested by fever, chills, headache, nausea, bronchospasm, hypotension and angioedema [5]. The majority of these reactions are mild, occur during the first infusion, and are less frequent with subsequent infusions. Severe mucocutaneous reactions and fatal infusion reactions (including adult respiratory distress syndrome, myocardial ischaemia and arrhythmias) have very rarely been reported.

Antibodies directed against the murine component of rituximab, termed human anti-chimeric antibodies, may develop, but their exact incidence and clinical significance are uncertain. Albert et al. [6] found anti-chimeric antibodies in approximately a third of SLE patients treated with rituximab and while their development may be associated with poor B-cell depletion, interestingly it does not appear to alter the clinical response [7]. The incidence in many other diseases has not be thoroughly or systemically assessed. A small proportion of patients with antibodies develop serum sickness, characterized by rash, fever and arthralgia, 1-2 weeks after administration of the drug, which may influence subsequent drug use.

Infectious complications are more common, occurring in up to $50 \%$ of patients in the early post-treatment period, but are usually mild. They often comprise of upper respiratory tract infections, and viral infections with herpes zoster and influenza. More serious infections are rare, but reactivation of mycobacterial infections, hepatitis $\mathrm{B}, \mathrm{CMV}$ and JC polyomavirus can occur following rituximab treatment, with some practitioners adding in viral and bacterial prophylaxis for the duration of B-cell depletion. Progressive multifocal leukoencephalopathy (PML) is perhaps the most significant complication resulting from infection or reactivation of JC virus, and leads to an often-fatal demyelinating disease of the CNS. Carson et al. [8], however, identified only 57 cases of PML amongst patients treated with rituximab from its license in 1997 up until 2008 and many of those patients had underlying conditions which themselves were risk factors for PML development (such as lymphoproliferative diseases) and had also been treated with other immunosuppressive therapies.

Longer-term data on the safety of rituximab is beginning to emerge, including in the setting of treatment for systemic vasculitis. Smith et al. [9] described safe repeat treatment with rituximab over a 2-year period in the setting of maintenance therapy for AAV (total dose $6 \mathrm{~g}$ ), findings corroborated by both Rhee et al. [10], and longterm follow-up in the rituximab in ANCA vasculitis (RAVE) trial [11]. However, low immunoglobulin levels and an increased risk of infections may complicate lon- ger-term rituximab use. Besada et al. [12] reviewed the outcome of 35 patients treated with rituximab induction and then maintenance over a period of up to 7 years (median total rituximab dose of $8 \mathrm{~g}$ ). All the patients had a clinical response, but $37 \%$ had to discontinue rituximab treatment over this time frame, mainly due to hypogammaglobulinaemia. Moreover, $26 \%$ of patients had severe infections and the risk factors identified were the cumulative dose of previous cyclophosphamide (CYP), a low CD4 count, and a significant drop in total immunoglobulins after the first rituximab infusion. In addition, $29 \%$ developed chronic infections and the risk factors for this were low IgG levels and the cumulative rituximab dose. It is therefore important to monitor immunoglobulin levels following long-term or repeated rituximab therapy and remain vigilant for early signs of infection.

\section{Clinical Use of Rituximab}

Significant recent trials and major cohort studies of rituximab use in glomerular disease are summarized in table 1 . For some conditions only smaller cohorts or case studies are available and it should be remembered that they are subject to significant reporting bias, with fewer published studies reporting a lack of benefit.

\section{Systemic Lupus Erythematosus and Lupus Nephritis}

SLE is the prototypic immune complex disease involving the production of a wide range of autoantibodies with deposition of immune complexes in various organs. It is therefore not surprising that rituximab has been used in this setting. Renal involvement is common in SLE (up to $75 \%$ of patients have some abnormality during the course of disease) and it remains the strongest predictor of overall morbidity and mortality. Whilst 5 -year survival among patients with class IV nephritis has improved over the last 50 years (from $17 \%$ to over $80 \%$ ), there remains a significant mortality, and there has been less improvement in the rates of end-stage kidney disease (with $10-20 \%$ of patients with lupus nephritis (LN) needing renal replacement therapy) despite recent advances in management [13].

The primary aim in the management of $\mathrm{LN}$ is the induction of remission; this greatly improves both patient and renal survival (with $95 \%$ of patients and $94 \%$ renal survival at 10 years if remission is achieved rather than $60 \%$ of patients and $31 \%$ renal survival at 10 years if remission is not achieved) [14]. Trials have established the role of low-dose CYP (Euro-Lupus) and mycophenolate 
Table 1. Recent trials and cohort studies of rituximab treatment in various glomerular diseases

\begin{tabular}{|c|c|c|c|c|c|c|c|}
\hline Reference & Trial type & $\mathrm{n}$ & $\begin{array}{l}\text { Dose } \\
\text { rituximab }\end{array}$ & $\begin{array}{l}\text { Indication } \\
\text { rituximab }\end{array}$ & Other IS & Definition response/endpoints & Outcome \\
\hline
\end{tabular}

\begin{tabular}{|c|c|c|c|c|c|}
\hline \multicolumn{6}{|l|}{ SLE } \\
\hline $\begin{array}{l}\text { UK-BIOGEAS } \\
{[20]}\end{array}$ & $\begin{array}{l}\text { Pooled } \\
\text { analysis }\end{array}$ & 164 & $\begin{array}{l}56 \% 2 \times 1 \mathrm{~g} \\
44 \% \\
375 \mathrm{mg} / \mathrm{m}^{2}\end{array}$ & $\begin{array}{l}10 \% \text { first line } \\
44 \% \text { relapse } \\
46 \% \text { refractory }\end{array}$ & $\begin{array}{l}99 \% \text { steroid } \\
76 \% \text { other IS } \\
\text { (MMF or } \\
\text { CYP) }\end{array}$ \\
\hline
\end{tabular}

CR: Normal serum creatinine, inactive urinary sediment and 24-hour urinary albumin $>0.5 \mathrm{~g}$ PR: $>50 \%$ improvement in all renal parameters that were abnormal at baseline, with no deterioration in any parameter 6 and 12 months

\begin{tabular}{|c|c|c|c|c|c|}
\hline $\begin{array}{l}\text { EXPLORER } \\
{[23]}\end{array}$ & $\mathrm{RCT}$ & 257 & $\begin{array}{l}2 \times 1 \mathrm{~g}(1 \text { and } \\
6 \text { months })\end{array}$ & $\begin{array}{l}\text { Refractory } \\
\text { disease } \\
\text { (extrarenal) }\end{array}$ & $\begin{array}{l}\text { Steroid and } \\
\text { other IS } \\
\text { (MMF, AZA } \\
\text { or MTX) }\end{array}$ \\
\hline
\end{tabular}

CR: BILAG C scores or better in all a BILAG A score or 2 new domains organs at week 24 without experiencing a severe flare (1 new domain with with a BILAG B score) from day 1 to week 24 , and maintaining this response without a moderate or severe flare (at least 1 new domain with a BILAG A or B score) to week 52 PR: (1) achieving BILAG C scores or better at week 24 and maintaining this response without a new BILAG A or B score for 16 consecutive weeks, (2) achieving no more than 1 organ with a BILAG B score at week 24 without achieving at least 1 new BILAG A or B score to week 52, or (3) achieving a maximum of 2 BILAG B scores at week 24 without developing BILAG A or B scores in new domains until week 52 if the baseline BILAG score for the patient was $1 \mathrm{~A}$ score plus at least $2 \mathrm{~B}$ scores, at least $2 \mathrm{~A}$ scores, or at least $4 \mathrm{~B}$ scores

\begin{tabular}{|c|c|c|c|c|c|}
\hline $\begin{array}{l}\text { LUNAR } \\
{[24]}\end{array}$ & RCT & 144 & $\begin{array}{l}2 \times 1 \mathrm{~g}(1 \text { and } \\
6 \text { months })\end{array}$ & $\begin{array}{l}\text { Class II or IV } \\
\text { lupus nephritis }\end{array}$ & $\begin{array}{l}\text { Steroids and } \\
\text { MMF }\end{array}$ \\
\hline
\end{tabular}

\begin{tabular}{|c|c|c|c|c|c|}
\hline $\begin{array}{l}\text { RITUXILUP } \\
\text { 25] }\end{array}$ & $\begin{array}{l}\text { Observa- } \\
\text { tional }\end{array}$ & 50 & $\begin{array}{l}2 \times 1 \mathrm{~g} \text { (days } \\
1 \text { and } 15)\end{array}$ & $\begin{array}{l}\text { Class III, IV or } \\
\text { V lupus } \\
\text { nephritis }\end{array}$ & $\begin{array}{l}\text { Pulsed steroid } \\
\text { only and } \\
\text { MMF }\end{array}$ \\
\hline
\end{tabular}

CR: Normal serum creatinine level if abnormal at baseline or a serum creatinine rise $<15 \%$ if normal at baseline, inactive urinary sediment ( $<5 \mathrm{RBCs} / \mathrm{hpf}$ and absence of RBC casts), and uPCR $<50$

PR: Serum creatinine rise $<15 \%$ of baseline, urinary sediment not significantly worse (RBCs/hpf $<50 \%$ above baseline and no RBC casts), and at least a $50 \%$ decrease in proteinuria (uPCR $<100$ if baseline $<300$ or uPCR $<300$ if baseline $>300$ ) NR: Not meeting criteria CR or PR, early termination, missing data or initiation new IS prior to week 52 At 1 year

Renal remission $=$ serum creatinine no greater than $15 \%$ above baseline CR: uPCR $<50 \mathrm{mg} / \mathrm{mmol}$ PR: uPCR $>50 \mathrm{mg} / \mathrm{mmol}$ but nonnephrotic and $>50 \%$ reduction
CR: 27\% (6/12), $30 \%(12 / 12)$ PR: $40 \%(6 / 12)$, $37 \%(12 / 12)$ NR: $33 \%$ Any response at 52 weeks: $28 \%$ placebo, $29 \%$ rituximab (placebo vs. rituximab) No significant difference
CR: 26.4 vs. $30.6 \%$ PR: 30.6 vs. $15.3 \%$ (rituximab vs. placebo) No significant difference 
Table 1 (continued)

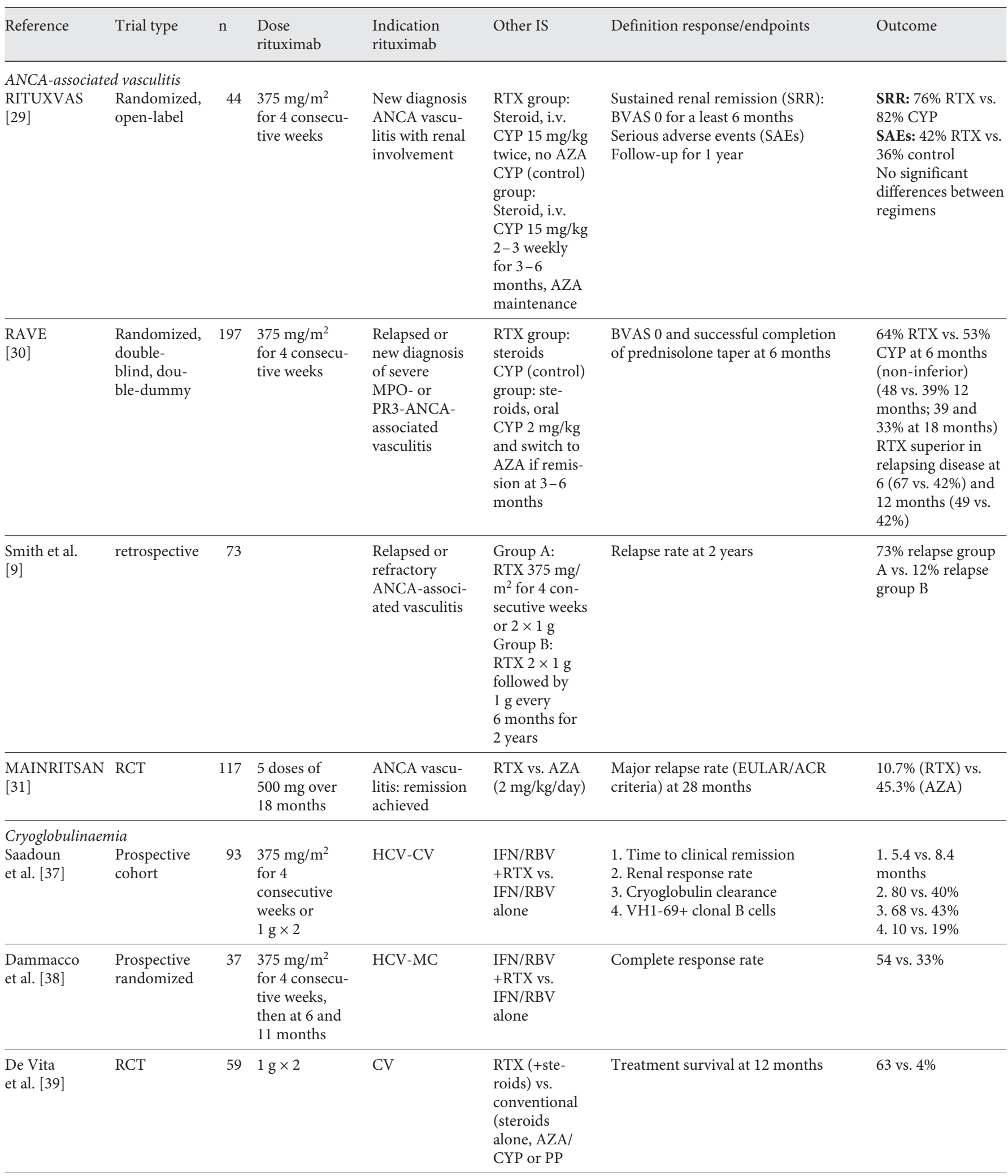


Table 1 (continued)

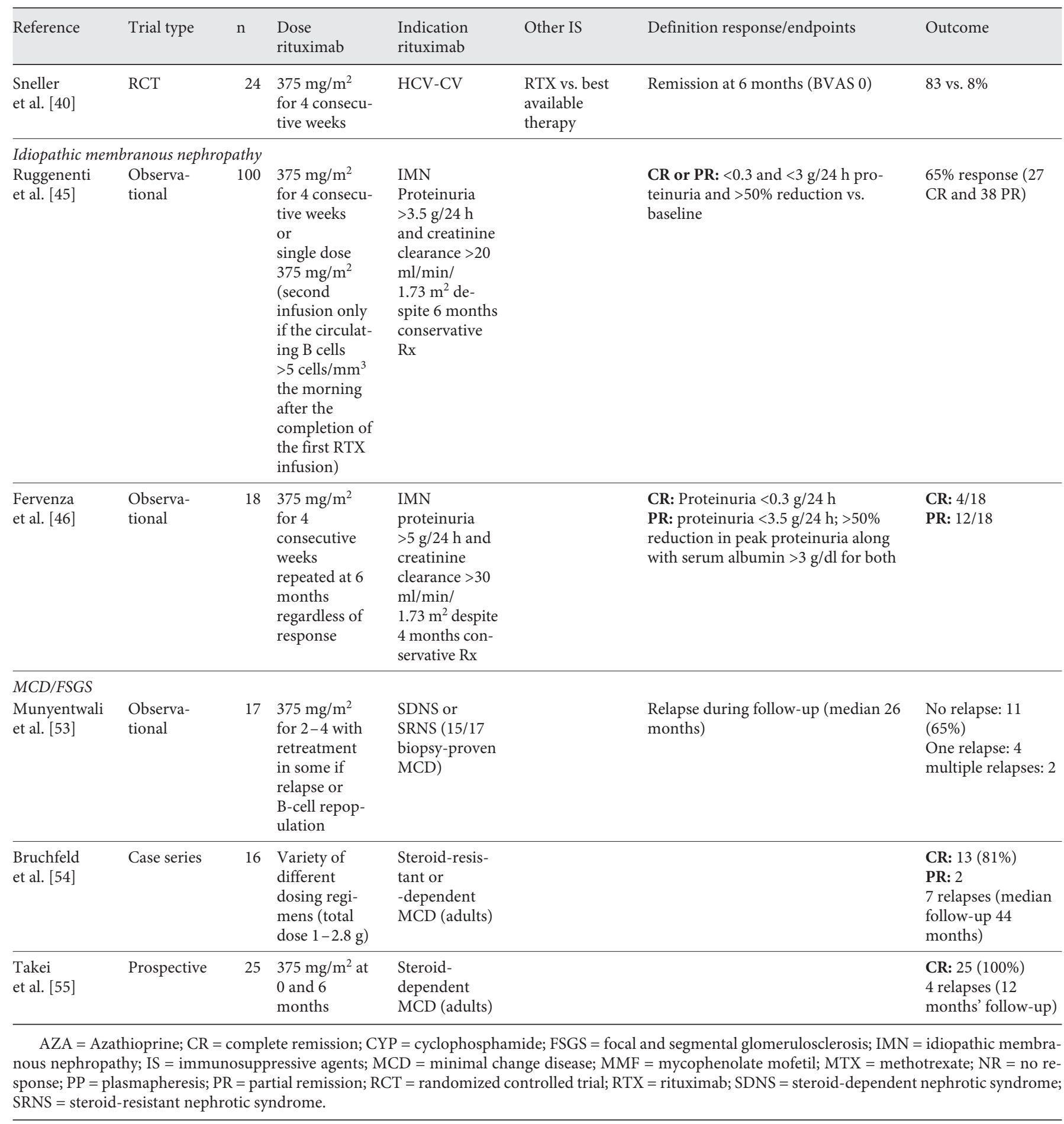

mofetil (MMF) (ALMS - induction/phase 1) as induction agents in $\operatorname{LN}[15,16]$, with most patients maintained on MMF or azathioprine (AZA) (found to be equivalent in the Euro-Lupus Maintain study, but with MMF superior- ity in the ALMS maintenance study) $[17,18]$. However, significant numbers of patients demonstrate inadequate or slow responses to these agents with, for example, just over a $50 \%$ response rate at 24 weeks using either CYP or 
MMF in the ALMS study, and 16\% treatment failure in the low-dose CYP arm of Euro-Lupus. In addition, these agents have significant side effects and some tolerability issues, particularly relevant in a disease that affects predominantly young women. Moreover, all these regimens are based on significant steroid usage, which is poorly tolerated by many patients, is associated with particular adverse events, and may be a significant contributor to the increased risk of premature cardiovascular disease and death in this patient population [19]. It is in this setting that rituximab has been tested.

Initial data on the use of rituximab induction in LN comes from the UK-BIOGEAS registry, which pooled data from 164 patients with biopsy-proven LN who were treated with rituximab across a number of European centres [20]. Rituximab was used as first-line therapy in $10 \%$, for disease relapse in $44 \%$ and for refractory disease in $46 \%$ (with the majority having been previously treated with CYP, AZA or MMF). Both the $1 \mathrm{~g} \times 2$ and 375 $\mathrm{mg} / \mathrm{m}^{2} \times 4$ dosing regimens were used. The majority of patients were also treated with steroids and $76 \%$ were treated with another immunosuppressive (CYP or MMF). Complete response (CR) was defined as a normal serum creatinine with inactive urinary sediment and 24-hour urinary albumin $<0.5 \mathrm{~g}$, while a partial response (PR) was a $>50 \%$ improvement in all renal parameters that were abnormal at baseline, with no deterioration in any parameter. A CR or PR was seen in $67 \%$ of patients at 6 and 12 months.

Whilst this and other retrospective studies [21, 22] have suggested a role for rituximab in SLE, evidence for benefit in randomized control trials is lacking. Two randomized controlled trials (RCTs) have evaluated the role of rituximab in extrarenal (EXPLORER) and renal (LUNAR) lupus, but both failed to reach their primary endpoint $[23,24]$.

EXPLORER studied 257 patients with moderate-severely active extrarenal lupus (as defined by a BILAG A score in at least one organ system or a BILAG B score in at least two organ systems) despite background immunosuppressive therapy using MMF, AZA, or methotrexate. All patients continued their background immunosuppression in addition to starting a course of higher-dose steroids (commencing at $0.5-1 \mathrm{mg} / \mathrm{kg}$ prednisolone and weaning over 52 weeks). They were randomized in a 2:1 ratio to $1 \mathrm{~g}$ rituximab or placebo given on days $1,15,168$, and 182. No difference was found between the two groups in terms of response to treatment, determined by changes in BILAG scores, at 52 weeks. In this trial the predominant disease activity at entry was related to mucocutane-

Update on Rituximab ous or musculoskeletal systems. These features are readily responsive to steroids and may therefore not have allowed a further clinical benefit to be seen following rituximab use.

By contrast, LUNAR studied 144 patients with biopsyproven class III or IV LN. This was an add-on study in which all patients were treated with steroids using pulsed intravenous methylprednisolone followed by daily oral prednisolone starting at $0.75 \mathrm{mg} / \mathrm{kg} /$ day and weaned to $<10 \mathrm{mg}$ /day by week 16, as well as MMF (target dose $3 \mathrm{~g} /$ day). Patients were randomized in a 1:1 ratio to $1 \mathrm{~g}$ rituximab or placebo on days $1,15,168$, and 182 . The primary endpoint was overall (CR and PR) renal response at 52 weeks. CR was defined in this trial as a normal serum creatinine level if abnormal at baseline or a serum creatinine rise $<15 \%$ if normal at baseline, inactive urinary sediment ( $<5 \mathrm{RBCs} / \mathrm{hpf}$ and absence of $\mathrm{RBC}$ casts), and urinary protein creatinine ratio (uPCR) $<50 \mathrm{mg} / \mathrm{mmol}$; PR was defined as a serum creatinine rise $<15 \%$ of baseline, urinary sediment not significantly worse (RBCs/hpf $<50 \%$ above baseline and no RBC casts), and at least a 50\% decrease in proteinuria (uPCR $<100$ if baseline $<300$ or uPCR $<300$ if baseline $>300$ ); whilst patients were classified as having no response (NR) if they did not meet the criteria for CR or PR, terminated treatment early, if there was missing data or if new immunosuppression was initiated prior to week 52 . There was no significant difference between the renal response rates at week 52 in the rituximab or placebo arms. Overall response rates were $56.9 \%$ with rituximab and $45.8 \%$ for placebo: CR 26.4 vs. $30.6 \%$ and PR 30.6 vs. $15.3 \%$ (rituximab vs. placebo). There was, however, a significantly greater improvement in serological markers (anti-dsDNA and complement levels) in the rituximab-treated group and subgroup analysis suggested a potential benefit with regard to $P R$ rates.

The two RCTs appeared to be at odds with the previous uncontrolled experience and there has been much debate about whether the trials were inadequately designed or powered to tease out an additional benefit of rituximab over conventional therapy. The LUNAR study set a fairly stringent composite endpoint and was powered to detect a $20 \%$ increase in CR and a 5\% increase in PR. There was no difference in CR but a 15\% increase in PR in the rituximab group. The trial, however, was underpowered for this to reach significance. In addition to the size of the study, duration of follow-up may also have been an issue. Given the response in serological markers with rituximab during the trial period, there may have been a lag with the clinical response and a potentially greater number of complete responders over a longer follow-up period. 
There remain many advocates for the use of rituximab in $\mathrm{LN}$ and its real benefit may be in developing steroid minimization or avoidance regimens. Data reporting a steroid-sparing maintenance regimen in active LN (RITUXILUP), using pulsed intravenous methylprednisolone, rituximab $1 \mathrm{~g}$ at days 1 and 15, and maintenance MMF has recently been published with encouraging results [25]. In 50 patients who were treated with this regimen, $72 \%$ achieved a CR (serum creatinine no greater than $15 \%$ above baseline and uPCR $<50 \mathrm{mg} / \mathrm{mmol}$ ) and $18 \%$ achieved a PR (serum creatinine no greater than $15 \%$ above baseline and uPCR $>50 \mathrm{mg} / \mathrm{mmol}$ but non-nephrotic and $>50 \%$ reduction). This protocol is now being tested against a conventional steroid and MMF regimen in an ongoing RCT.

\section{Antineutrophil Cytoplasm Antibody AAV}

Renal involvement in AAV usually manifests as a pauci-immune focal necrotizing crescentic glomerulonephritis (GN), often with rapidly progressive kidney injury. This may be part of a systemic vasculitis such as granulomatosis with polyangiitis or microscopic polyangiitis or may be limited to the kidney (renal-limited vasculitis). As with SLE, treatment consists of induction and maintenance phases but unlike SLE there is robust evidence for the use of rituximab in both the induction and maintenance phases of the disease.

Numerous studies including key EUVAS trials established a role for steroids and CYP as induction therapy in AAV. The CYCLOPS study demonstrated that in conjunction with steroids, pulsed intravenous CYP was as effective as daily oral CYP in inducing remission and resulted in a reduced cumulative CYP dose with less leukopenia [26]. However, more recent long-term follow-up from this study demonstrated that the pulsed regimen was associated with a higher risk of relapse ( 21 vs. $40 \%$ (daily oral vs. pulsed) relapse at a median follow-up of 4.3 years) [27].

However, such early CYP protocols carried significant toxicity, and much of the early mortality in AAV was thought to be due its use alongside steroids [28]. It was as a result of this toxicity that alternative agents were eagerly sought and the reason for the adoption of rituximab in early cohort studies. Since then the anecdotal reports were translated into randomized trials and a balanced view of the role of rituximab has emerged. Two randomized trials, rituximab versus CYP in AAV (RITUXVAS) and rituximab in AAV (RAVE), have demonstrated the efficacy of rituximab as an induction agent in AAV and it was on the basis of these that the Food and Drug Admin- istration and the European Medicines Agency recently granted licenses for its use $[29,30]$.

In RITUXVAS, 44 patients with newly diagnosed AAV and advanced renal involvement received a standard glucocorticoid regimen and were randomized in a 3:1 ratio to either rituximab ( $375 \mathrm{mg} / \mathrm{m}^{2}$ for 4 consecutive weeks) with two doses of intravenous CYP (with the first and third rituximab infusions) and no AZA maintenance, or intravenous CYP (every 2-3 weeks for 3-6 months) followed by AZA maintenance. The primary endpoints were sustained remission rates (BVAS of 0 for at least 2 months) at 12 months and severe adverse events. No difference was found between the groups with regard to either endpoint, with sustained remission achieved in $76 \%$ of the rituximab group and $82 \%$ of the control group. Interestingly, there was also no difference in serious adverse events ( $42 \%$ rituximab vs. $36 \%$ control), and there was a high mortality rate of $18 \%$ at 1 year in both groups, reflecting the enrolled population of elderly AAV patients with advanced renal disease.

RAVE was a double-blind, placebo-controlled, noninferiority trial that included both newly diagnosed and relapsing patients with MPO- and PR3-AAV. A total of 197 patients with severe disease (BVAS $>2$ ) were randomized to a rituximab-based regimen (rituximab $375 \mathrm{mg} / \mathrm{m}^{2}$ for 4 consecutive weeks) or a CYP-based regimen (using oral CYP). If patients achieved remission between 3 and 6 months they were switched to AZA in the CYP group and to placebo in the rituximab group. Both groups received high-dose glucocorticoids, which were tapered over 5 months in the absence of disease flare. The primary endpoint was a BVAS of 0 and successful completion of the prednisolone taper at 6 months. This was achieved in $64 \%$ of patients in the rituximab group compared with $53 \%$ in the CYP group, reaching significance for non-inferiority. Notably, in the subgroup analysis, rituximab was significantly more efficacious than CYP in achieving the primary endpoint in the setting of relapsing disease ( 67 vs. $42 \%$, rituximab vs. CYP, respectively). No difference was found between the treatment groups when comparing outcome according to ANCA type, renal function, severity of disease (including alveolar haemorrhage), or age of the patients. Again, serious adverse events were equally common in both treatment groups.

These two studies confirmed that rituximab-based regimens are as effective as CYP in achieving remission in AAV, in patients presenting with advanced renal disease (including dialysis dependency) and alveolar haemorrhage, while it appeared superior in those with relapsing disease. However, neither study demonstrated a bet- 
ter adverse effect profile despite avoidance of CYP and this may suggest that much of the morbidity and mortality previously ascribed to CYP may be due to highdose steroids used in both trials. Longer-term follow-up from the RAVE trial has recently been published [11]. The groups were followed to 18 months. As stated, the rituximab group had received no maintenance therapy after 6 months whereas the CYP group had received AZA. CR rates in the rituximab group were 64,47 and $39 \%$ at 6,12 and 18 months, respectively, compared with 53, 39 and $33 \%$ with CYP-AZA. In those with relapsing disease, the superior effect of rituximab was maintained at 12 months but not at 18 months at which time the majority of patients in the rituximab group had repopulated their B cells, suggesting that in those with relapsing disease, further doses of rituximab may be warranted.

At what stage rituximab should be re-administered has been debated. Preemptive re-treatment with rituximab every 6 months has been shown to be of benefit with regard to relapse rates when compared with a watchful policy of re-treating at signs of clinical relapse. Smith et al. [9] demonstrated that retreating with $1 \mathrm{~g}$ rituximab every 6 months for 2 years reduced the rate of relapse from 73 to $12 \%$ compared with those given no further rituximab treatment post-induction.

Several ongoing randomized trials investigating the use of rituximab as maintenance therapy are addressing the issue of efficacy using different dosing regimens compared with standard therapies. An open-label study in France (MAINRITSAN) compared AZA ( $2 \mathrm{mg} / \mathrm{kg} /$ day) to rituximab (5 doses of $500 \mathrm{mg}$ over 18 months) in 117 patients with AAV in whom remission had been achieved [31]. A reduced relapse rate ( 45.3 vs. $10.7 \%$, respectively) was demonstrated at 28 months in the rituximab arm. This has led to a second trial (MAINRITSAN 2), which is comparing two differing treatment strategies, the first replicates the previous dosing in MAINRITSAN and the second stipulates a first dose of rituximab which is only repeated 6 months later if the B-cell count is $>0 / \mathrm{mm}^{3}$ or the ANCA titre is rising [32]. The RITAZAREM study is currently recruiting patients and comparing rituximab maintenance ( $1 \mathrm{~g}$ every 4 months) with AZA at standard doses [33]. Our own recent retrospective data [61] have demonstrated that in AAV (but not SLE) treatment with a single dose of rituximab which is repeated only if the CD19 count is not depleted (to $0.005 \mathrm{cell} / \mathrm{mm}^{3}$ or less) provides equivalent remission induction as a standard two $1 \mathrm{~g}$ doses or the weekly $375 \mathrm{mg} / \mathrm{m}^{2}$ regimen, suggesting that further refinements of the treatment regimens may be pos- sible, altering the significant economic burden of using monoclonal antibody therapy.

Cryoglobulinaemic Vasculitis and Glomerulonephritis

Most cases of cryoglobulinaemic vasculitis (CV) and GN are secondary to viral (usually hepatitis C)-driven clonal B-cell expansion. However, geographical differences occur, and while hepatitis $\mathrm{C}$-associated mixed cryoglobulinaemia is common in Southern Europe, cases of idiopathic mixed essential cryoglobulinaemia unrelated to viral infection may still be found in Northern Europe $[34,35]$. B-cell expansion, by whatever means, results in the synthesis of high levels of IgM with rheumatoid factor activity, and these antibodies, in turn, bind viral particles and polyclonal IgG forming mixed cryoglobulins. The immune complexes bind endothelial cells and promote local complement activation and recruitment of inflammatory cells, which mediate a leukocytoclastic small vessel vasculitis often involving the skin, nervous system and the kidney (frequently resulting in a membranoproliferative GN).

Cryoglobulins are commonly found in chronic hepatitis $\mathrm{C}$ infection but may be clinically silent, or produce only mild disease (affecting only the skin). Rarely, they may be associated with severe organ damage and their management is complicated by the risk of traditional immunosuppression in patients with active viraemia. A recent review summarizes an approach to the management of hepatitis C-related CV (HCV-CV) [36]. Therapy is targeted at the underlying infection (using antivirals alone) in mild disease, while immunosuppression targeting the $\mathrm{B}$-cell clones is reserved for more severe disease and this is the setting for rituximab use.

Rituximab in combination with antivirals is more effective than antivirals alone. Saadoun et al. [37] compared the use of pegylated-interferon- $\alpha$ /ribavirin (Peg-IFN- $\alpha$ / Rbv) alone with Peg-IFN- $\alpha / \mathrm{Rbv}$ in conjunction with rituximab $\left(375 \mathrm{mg} / \mathrm{m}^{2} \times 4\right.$ or $\left.1 \mathrm{~g} \times 2\right)$ in 93 patients with $\mathrm{HCV}-\mathrm{CV}$, the majority of whom had histological confirmation of disease. There was a shorter time to clinical remission (5.4 vs. 8.4 months), better renal response rates ( 80 vs. $40 \%$ ) defined as normalization of creatinine and disappearance of haemoproteinuria, and higher rates of cryoglobulin clearance (68 vs. $43 \%$ ) in the rituximab group. Treatment was tolerated well without worsening of HCV viraemia in the rituximab arm.

Dammacco et al. [38] found a similar benefit of adding rituximab to antiviral therapy and reported CR rates (disappearance or improvement in clinical features, disappearance of cryoglobulins, undetectable HCV RNA and 
disappearance of B-cell clonality from blood) in $54 \%$ in the combined rituximab/antiviral-treated cohort compared with $33 \%$ in the antiviral-alone treatment group. Patients were followed up for 3 years after the completion of treatment. Of those that responded, $83 \%$ in the combined rituximab/antiviral group maintained CR to 3 years as opposed to only $40 \%$ in the antiviral group.

As regards comparison of rituximab to other immunosuppressives, outcomes favour rituximab in two recent RCTs $[39,40]$. De Vita et al. [39] randomized 59 patients with CV to treatment with rituximab $(1 \mathrm{~g} \times 2$, with steroids) or to conventional treatment [one of: steroids alone (59\%), AZA (10\%), CYP (14\%), or plasmapheresis (17\%)]. In those with hepatitis $\mathrm{C}$, antiviral therapy had previously failed, been poorly tolerated or was considered to be contraindicated. The primary endpoint was the proportion of patients continuing to take their treatment (i.e. survival of treatment) at 12 months. This was achieved in $63 \%$ of the rituximab group compared with $4 \%$ in the non-rituximab group. The main reason for treatment failure in the non-rituximab arm was lack of response or worsening target organ manifestations. There were 7 patients with GN in the rituximab arm, 57\% of whom responded to treatment.

Sneller et al. [40] randomized 24 patients with HCV$\mathrm{CV}$ who had failed to respond to antiviral therapy to treatment with rituximab $\left(375 \mathrm{mg} / \mathrm{m}^{2}\right.$ weekly for 1 month) or standard treatment with augmented immunosuppression or introduction of alternative immunosuppression. The primary endpoint of remission at 6 months was achieved in $83 \%$ of patients in the rituximab arm compared with $8 \%$ of controls. The majority of patients in the rituximab arm who were on steroids at entry had been weaned off these by 6 months and there was no worsening of HCV infection in the rituximab group. Four patients in each arm had glomerular involvement at entry - all of those in the control group experienced a decline in eGFR over 6 months whereas all of those in the rituximab group either maintained stable renal function or had improvement in eGFR.

Hence, rituximab has a defined role in management of HCV-CV. It is important to note, however, that unlike $\mathrm{HCV}$, rituximab is currently contraindicated in hepatitis $\mathrm{B}$ or HIV infection with detectable viral load.

Rituximab also appears to be of benefit in the management of cases of mixed essential (non-infectious) CV. In the CryoVas survey of non-infectious $\mathrm{CV}$, rituximab with corticosteroids showed greater therapeutic efficacy compared with corticosteroids alone or with alkylating agents in achieving complete clinical, renal, and immunologic response [41]. Infection rates were high, however, with $29 \%$ of patients experiencing severe infections with this regimen.

\section{Primary Glomerular Diseases}

Idiopathic Membranous Nephropathy

There is considerable ongoing debate about the use of immunosuppression in idiopathic membranous nephropathy (IMN). Recent KDIGO guidelines suggest that in those that are treated with immunosuppression, the use of 6 months of alternating monthly cycles of steroids and an alkylating agent (CYP or chlorambucil) (Ponticelli regimen) be used as first line [42]. This regimen, however, may be contraindicated for many (due to the high steroid dosages) or poorly tolerated [43]. Calcineurin inhibitors may be used as second-line agents but are associated with significant relapse rates upon cessation and long-term concerns regarding nephrotoxicity. In addition, the recent membranous study comparing these regimens head to head clearly demonstrated that in patients with declining renal function, calcineurin-based regimens are associated with poorer long-term renal outcome than steroid/alkylating agent-based regimens [44]. These data, in addition to the recent advances in our understanding of the pathogenesis of IMN as an autoantibody-mediated disease, makes B-cell depletion an attractive and rational therapeutic strategy.

There are promising observational data on the use of rituximab but data from randomized trials is still lacking. Remuzzi and colleagues [45] first described rituximab use in IMN in the early 2000s and since then this group has treated all patients with biopsy-proven IMN (creatinine clearance $>20 \mathrm{ml} / \mathrm{min} / 1.73 \mathrm{~m}^{2}$ and proteinuria $>3.5 \mathrm{~g} /$ $24 \mathrm{~h}$ despite 6 months of full-dose ACEi and optimization of conservative therapy) with rituximab as first-line treatment (using $375 \mathrm{mg} / \mathrm{m}^{2}$ weekly for 4 weeks up until 2005; after this, a single dose of $375 \mathrm{mg} / \mathrm{m}^{2}$ was given, with a second infusion of the same dose only if the level of circulating $\mathrm{B}$ cells the morning after completion of the first rituximab infusion was $>5$ cells $/ \mathrm{mm}^{3}$ ). The outcomes of 100 consecutive patients treated in this way have recently been published [45]. The median follow-up was 29 months during which 65 patients achieved a CR $(<0.3 \mathrm{~g} / 24 \mathrm{~h}$ proteinuria and $>50 \%$ reduction vs. baseline $)$ or PR $(<3 \mathrm{~g} / 24 \mathrm{~h}$ proteinuria and $>50 \%$ reduction vs. baseline). 18 of these patients relapsed, 11 of whom responded to a further course of rituximab.

Fervenza et al. [46] also published encouraging results from a small cohort of patients with IMN followed up for 2 years. Patients were entered if they had biopsy-proven 
IMN and persistent proteinuria $>5 \mathrm{~g} / 24 \mathrm{~h}$ (creatinine clearance $>30 \mathrm{ml} / \mathrm{min} / 1.73 \mathrm{~m}^{2}$ ) despite 4 months of maximum conservative treatment. Patients were treated with $375 \mathrm{mg} / \mathrm{m}^{2}$ rituximab weekly for 4 weeks repeated at 6 months regardless of clinical response. Eighteen patients (out of 20) completed 24 months of follow-up at which point 4 were in CR and 12 in PR (CR defined as proteinuria $<0.3 \mathrm{~g} / 24 \mathrm{~h}, \mathrm{PR}$ as proteinuria $<3.5 \mathrm{~g} / 24 \mathrm{~h} ;>50 \%$ reduction in peak proteinuria along with serum albumin $>3 \mathrm{~g} / \mathrm{dl}$ for both).

Hence, early reports are promising but randomized data directly comparing rituximab to other immunosuppressive regimens and information on the optimal dose and duration of treatment is currently lacking. Several randomized trials are currently recruiting to compare rituximab against conservative management alone (GEMRITUX) or cyclosporine (MENTOR), and a trial is planned to compare rituximab in conjunction with tacrolimus with a Ponticelli-like regimen (STARMEN) [47-49].

\section{Minimal Change Disease and Focal Segmental}

Glomerulosclerosis

A good response to steroids is seen in the majority of patients with minimal change disease (MCD). However, steroid dependency will develop in up to $40 \%$. In these, alkylating agents, calcineurin inhibitors, antiproliferative and immunomodulatory agents have been used as steroid-sparing agents, with a mixed response reported. There are increasing data from observational studies on the use of rituximab in steroid-resistant (SRNS) and steroid-dependent (SDNS) nephrotic syndrome in children [usually secondary to MCD or focal segmental glomerulosclerosis (FSGS)] [50, 51]. Less has been published with regard to adults, and randomized trials are lacking in both populations.

Ronco and colleagues [52] described a case of adult multirelapsing MCD treated successfully with rituximab in 2007 and recently reported a case series of 17 adults with SDNS or frequently-relapsing nephrotic syndrome (FRNS) treated with B-cell depletion [53]. All had been previously treated with prolonged steroid courses and the majority had received another immunosuppressant drug. 10 of the patients were treated after steroid-induced remission ( $\mathrm{uPCR}<100 \mathrm{mg} / \mathrm{mmol}$ ), the others were treated with higher levels of proteinuria. Eleven patients had no relapse at a median follow-up of 26.7 months and this was associated with a significant reduction in steroids and other immunosuppressive treatment. Rituximab was given at a dose of $375 \mathrm{mg} / \mathrm{m}^{2}$ weekly for 2-4 weeks with retreatment in 4 patients due to repopulation of B cells. Six patients relapsed during follow-up, usually in the setting of B-cell recovery. Four of these responded to a further course of steroids and rituximab while 2 patients suffered multiple relapses, and were unresponsive to treatment.

Bruchfeld et al. [54] report a Swedish cohort of 16 adult patients with steroid-dependent or -resistant MCD who were treated with rituximab (a variety of doses with total exposure ranging from 1 to $2.8 \mathrm{~g}$ ). Thirteen patients achieved CR (normalization of albumin and resolution of proteinuria), whilst 2 achieved a $\mathrm{PR}(>50 \%$ reduction in proteinuria). Rituximab use enabled discontinuation or tapering of steroid use to below levels where relapses had occurred in the past. Seven patients relapsed over a median follow-up of 44 months.

Takei et al. [55] undertook a prospective trial of rituximab use ( $375 \mathrm{mg} / \mathrm{m}^{2}$ at 0 and 6 months) in 25 adults with steroid-dependent MCD. All patients achieved a CR and rituximab use allowed a significant reduction in the dose of steroid used. There were 4 relapses over the course of 12 months' follow-up, all of which were associated with B-cell repopulation, suggesting a higher or repeated dose of rituximab may have been needed.

Data on rituximab specifically in primary FSGS is sparse and limited to case reports and very small case series. Randomized studies are needed to further evaluate the role of rituximab in both MCD and primary FSGS. NEPHRUTIX has completed recruitment to evaluate the role of rituximab in severe cyclosporine-dependent nephrotic syndrome in children but there are no active trials at present in adults [56].

\section{Other Glomerular Diseases}

Treatment of membranoproliferative GN in the setting of hepatitis $\mathrm{C}$ or cryoglobulinaemia is outlined above. There are few data on the use of rituximab in MPGN outside this setting or for the use of rituximab in IgA nephropathy. Sugiura et al. [57] prospectively assessed the role of a single dose of rituximab in 24 patients with a variety of glomerular diseases including 5 with IgA nephropathy and reported no benefit in those with IgA disease. There is, however, a trial currently recruiting comparing rituximab with conservative management in IgA nephropathy.

Similarly, data on the use of rituximab in fibrillary GN is limited. A recent series on the long-term renal outcome of fibrillary GN patients included 7 patients treated with rituximab [58]. Of these patients, $5(71 \%)$ achieved a renal response as compared to only 16 and $14 \%$ in those treated with other immunosuppression and without immunosuppression, respectively. Larger collaborative studies are 
needed to establish the role of immunosuppression in the management of fibrillary GN, in particular with regard to B-cell depletion.

Finally, reports have recently been published on the use of rituximab in anti-GBM disease [59]. Being an antibody-mediated disease, rituximab seems a rational choice of treatment. The authors identified 5 cases of anti-GBM disease treated with rituximab, 4 of whom recovered renal function and remained dialysis-independent. However, given the rarity of anti-GBM disease and the paucity of clinical trial data on this condition, it seems unlikely that a trial comparing rituximab with standard CYP-based treatment will ever be carried out. It therefore remains an option for those patients in whom CYP may be contraindicated or in whom it may want to be avoided.

\section{Conclusions}

Rituximab has an increasing role in a variety of different immune-mediated glomerular diseases. Evidence is robust in only a few, most notably ANCA-associated disease, and multiple trials are ongoing examining its role in others. It is generally a safe and well-tolerated drug, espe- cially in the short term. More data is required with regard to long-term use and optimal dosing regimens. Treatment targeted to B-cell response seems a rational approach, which has been reported in small cohorts and is now being tested in randomized trials. Lastly, there are significant cost implications with the use of rituximab as induction and/or maintenance therapy, but with the expiration of patent and the development of many bio-similars, as well as the possible use of lower doses adjusted to B-cell levels, the cost will be driven down [60].

\section{Key Points}

- Rituximab is a chimeric monoclonal antibody directed against the CD20 antigen on the surface of immature and mature B cells.

- It is licensed for use in AAV.

- It is used off-license to treat a variety of immune-mediated kidney diseases (e.g. LN, CV and IMN).

- It is safe and well tolerated in most.

- Long-term use may be complicated by hypogammaglobulinaemia and increased infectious complications.

- Optimal dosing is unclear.

- The development of bio-similars and dosing targeted to $\mathrm{B}$-cell response may reduce cost.

\section{References}

1 Ramanath V, Nistala R, Chaudhary K: Update on the role of rituximab in kidney diseases and transplant. Expert Opin Biol Ther 2012; 12:223-233.

-2 Salama AD, Pusey CD: Drug insight: rituximab in renal disease and transplantation. Nat Clin Pract Nephrol 2006;2:221-230.

-3 Anolik JH, Campbell D, Felgar RE, Young F, Sanz I, Rosenblatt J, et al: The relationship of Fc $\gamma$ RIIIa genotype to degree of B-cell depletion by rituximab in the treatment of systemic lupus erythematosus. Arthritis Rheum 2003;48:455-459.

4 Kimby E: Tolerability and safety of rituximab (MabThera). Cancer Treat Rev 2005;31:456473.

5 Mohrbacher A: B-cell non-Hodgkin's lymphoma: rituximab safety experience. Arthritis Res Ther 2005;7(suppl 3):S19-S25.

-6 Albert D, Dunham J, Khan S, Stansberry J, Kolasinski S, Tsai D, et al: Variability in the biological response to anti-CD20 B-cell depletion in systemic lupus erythematosus. Ann Rheum Dis2008;67:1724-1731.

-7 Thurlings RM, Teng O, Vos K, Gerlag DM, Aarden L, Stapel SO, et al: Clinical response, pharmacokinetics, development of human anti-chimaeric antibodies, and synovial tissue response to rituximab treatment in patients with rheumatoid arthritis. Ann Rheum Dis 2010;69:409-412.

8 Carson KR, Evens AM, Richey EA, Habermann TM, Focosi D, Seymour JF, et al: Progressive multifocal leukoencephalopathy after rituximab therapy in HIV-negative patients: a report of 57 cases from the Research on Adverse Drug Events and Reports project. Blood 2009;113:4834-4840.

-9 Smith RM, Jones RB, Guerry MJ, Laurino S, Catapano F, Chaudhry A, et al: rituximab for remission maintenance in relapsing antineutrophil cytoplasmic antibody-associated vasculitis. Arthritis Rheum 2012;64: 3760-3769.

10 Rhee EP, Laliberte KA, Niles JL: Rituximab as maintenance therapy for anti-neutrophil cytoplasmic antibody-associated vasculitis. Clin J Am Soc Nephrol 2010;5:1394-1400.

11 Specks U, Merkel PA, Seo P, Spiera R, Langford CA, Hoffman GS, et al: Efficacy of remission-induction regimens for ANCA-associated vasculitis. N Engl J Med 2013;369:417427.

12 Besada E, Koldingsnes W, Nossent JC: Longterm efficacy and safety of preemptive maintenance therapy with rituximab in granulo- matosis with polyangiitis: results from a single centre. Rheumatology 2013;52:2041-2047.

13 Lightstone L: The landscape after LUNAR: rituximab's crater-filled path. Arthritis Rheum 2012;64:962-965.

14 Korbet SM, Lewis EJ, Schwartz MM, Reichlin M, Evans J, Rohde RD: Factors predictive of outcome in severe lupus nephritis. Lupus $\mathrm{Ne}$ phritis Collaborative Study Group. Am J Kidney Dis 2000;35:904-914.

15 Houssiau FA, Vasconcelos C, D’Cruz D, Sebastiani GD, Garrido Ed Ede R, Danieli MG, et al: Immunosuppressive therapy in lupus nephritis: the Euro-Lupus Nephritis Trial, a randomized trial of low-dose versus highdose intravenous cyclophosphamide. Arthritis Rheum 2002;46:2121-2131.

16 Appel GB, Contreras G, Dooley MA, Ginzler EM, Isenberg D, Jayne D, et al: Mycophenolate mofetil versus cyclophosphamide for induction treatment of lupus nephritis. J Am Soc Nephrol 2009;20:1103-1112.

17 Houssiau FA, D’Cruz D, Sangle S, Remy P, Vasconcelos C, Petrovic R, et al: Azathioprine versus mycophenolate mofetil for long-term immunosuppression in lupus nephritis: results from the MAINTAIN Nephritis Trial. Ann Rheum Dis 2010;69:2083-2089. 
18 Dooley MA, Jayne D, Ginzler EM, Isenberg D, Olsen NJ, Wofsy D, et al: Mycophenolate versus azathioprine as maintenance therapy for lupus nephritis. N Engl J Med 2011;365:1886-1895.

$\checkmark 19$ Mosca M, Tani C, Carli L, Bombardieri S: Glucocorticoids in systemic lupus erythematosus. Clin Exp Rheumatol 2011;29(suppl 68):S126-S129.

20 Diaz-Lagares C, Croca S, Sangle S, Vital EM, Catapano F, Martinez-Berriotxoa A, et al: Efficacy of rituximab in 164 patients with biopsy-proven lupus nephritis: pooled data from European cohorts. Autoimmun Rev 2012;11: 357-364.

21 Ramos-Casals M, Soto MJ, Cuadrado MJ, Khamashta MA: Rituximab in systemic lupus erythematosus: a systematic review of off-label use in 188 cases. Lupus 2009; 18:767-776.

-22 Jonsdottir T, Zickert A, Sundelin B, Henriksson EW, van Vollenhoven RF, Gunnarsson I: Long-term follow-up in lupus nephritis patients treated with rituximab-clinical and histopathological response. Rheumatology 2013; 52:847-855.

23 Merrill JT, Neuwelt CM, Wallace DJ, Shanahan JC, Latinis KM, Oates JC, et al: Efficacy and safety of rituximab in moderately-to-severely active systemic lupus erythematosus: the randomized, double-blind, phase II/III systemic lupus erythematosus evaluation of rituximab trial. Arthritis Rheum 2010;62:222-233.

-24 Rovin BH, Furie R, Latinis K, Looney RJ, Fervenza FC, Sanchez-Guerrero J, et al: Efficacy and safety of rituximab in patients with active proliferative lupus nephritis: the lupus nephritis assessment with rituximab study. Arthritis Rheum 2012;64:1215-1226.

-25 Condon MB, Ashby D, Pepper RJ, Cook HT, Levy JB, Griffith M, et al: Prospective observational single-centre cohort study to evaluate the effectiveness of treating lupus nephritis with rituximab and mycophenolate mofetil but no oral steroids. Ann Rheum Dis 2013;72: $1280-1286$

26 De Groot K, Harper L, Jayne DR, Flores Suarez LF, Gregorini G, Gross WL, et al: Pulse versus daily oral cyclophosphamide for induction of remission in antineutrophil cytoplasmic antibody-associated vasculitis: a randomized trial. Ann Intern Med 2009;150: 670-680.

-27 Harper L, Morgan MD, Walsh M, Hoglund P, Westman K, Flossmann O, et al: Pulse versus daily oral cyclophosphamide for induction of remission in ANCA-associated vasculitis: long-term follow-up. Ann Rheum Dis 2012; 71:955-960.

-28 Little MA, Nightingale P, Verburgh CA, Hauser T, De Groot K, Savage C, et al: Early mortality in systemic vasculitis: relative contribution of adverse events and active vasculitis. Ann Rheum Dis 2010;69:1036-1043.

-29 Jones RB, Tervaert JW, Hauser T, Luqmani R, Morgan MD, Peh CA, et al: Rituximab versus cyclophosphamide in ANCA-associated renal vasculitis. N Engl J Med 2010;363:211220.
30 Stone JH, Merkel PA, Spiera R, Seo P, Langford CA, Hoffman GS, et al: Rituximab versus cyclophosphamide for ANCA-associated vasculitis. N Engl J Med 2010;363:221-232.

31 Terrier B, Pagnoux C, Karras A, Khouatra C, Aumaitre O, Cohen P, et al: Rituximab versus azathioprine for maintenance in antineutrophil cytoplasmic antibodies (ANCA)-associated vasculitis (MAINRITSAN): follow-up at 34 months. Presse Med 2013;42:778-779.

$32 \mathrm{http}: / /$ clinicaltrials.gov/show/NCT01731561.

$33 \mathrm{http} / / /$ clinicaltrials.gov/ct2/show/ NCT01697267.

-34 Annear NM, Cook HT, Atkins M, Pusey CD, Salama AD: Non-hepatitis virus associated mixed essential cryoglobulinemia. Kidney Int 2010;77:161-164.

35 Damoiseaux J, Cohen Tervaert JW: Diagnostics and treatment of cryoglobulinaemia: it takes two to tango. Clin Rev Allergy Immunol 2013, Epub ahead of print.

36 Dammacco F, Sansonno D: Therapy for hepatitis $\mathrm{C}$ virus-related cryoglobulinemic vasculitis. N Engl J Med 2013;369:1035-1045.

37 Saadoun D, Resche Rigon M, Sene D, Terrier B, Karras A, Perard L, et al: Rituximab plus Peg-interferon- $\alpha$ /ribavirin compared with Peg-interferon- $\alpha /$ ribavirin in hepatitis C-related mixed cryoglobulinemia. Blood 2010; 116:326-334.

38 Dammacco F, Tucci FA, Lauletta G, Gatti P, De Re V, Conteduca V, et al: Pegylated interferon- $\alpha$, ribavirin, and rituximab combined therapy of hepatitis $\mathrm{C}$ virus-related mixed cryoglobulinemia: a long-term study. Blood 2010;116:343-353.

- 39 De Vita S, Quartuccio L, Isola M, Mazzaro C, Scaini P, Lenzi M, et al: A randomized controlled trial of rituximab for the treatment of severe cryoglobulinemic vasculitis. Arthritis Rheum 2012;64:843-853.

40 Sneller MC, Hu Z, Langford CA: A randomized controlled trial of rituximab following failure of antiviral therapy for hepatitis $\mathrm{C}$ virus-associated cryoglobulinemic vasculitis. Arthritis Rheum 2012;64:835-842.

41 Terrier B, Carrat F, Krastinova E, Marie I, Launay D, Lacraz A, et al: Prognostic factors of survival in patients with non-infectious mixed cryoglobulinaemia vasculitis: data from 242 cases included in the CryoVas survey. Ann Rheum Dis 2013;72:374-380.

42 Kidney Disease: Improving Global Outcomes (KDIGO) Glomerulonephritis Work Group. KDIGO Clinical Practice Guideline for Glomerulonephritis. Kidney Int Suppl 2012;2: 139-274.

43 Ponticelli C, Glassock RJ: Glomerular diseases: membranous nephropathy - a modern view. Clin J Am Soc Nephrol 2013, Epub ahead of print.

-44 Howman A, Chapman TL, Langdon MM, Ferguson C, Adu D, Feehally J, et al: Immunosuppression for progressive membranous nephropathy: a UK randomised controlled trial. Lancet 2013;381:744-751.
45 Ruggenenti P, Cravedi P, Chianca A, Perna A, Ruggiero B, Gaspari F, et al: rituximab in idiopathic membranous nephropathy. J Am Soc Nephrol 2012;23:1416-1425.

46 Fervenza FC, Abraham RS, Erickson SB, Irazabal MV, Eirin A, Specks U, et al: Rituximab therapy in idiopathic membranous nephropathy: a 2-year study. Clin J Am Soc Nephrol 2010;5:2188-2198.

47 http://clinicaltrials.gov/show/NCT01508468.

$48 \mathrm{http} / / /$ clinicaltrials.gov/show/NCT01180036.

$49 \mathrm{http} / / /$ clinicaltrials.gov/show/NCT01955187.

50 Haffner D, Fischer DC: Nephrotic syndrome and rituximab: facts and perspectives. Pediatr Nephrol 2009;24:1433-1438.

51 Gulati A, Sinha A, Jordan SC, Hari P, Dinda AK, Sharma S, et al: Efficacy and safety of treatment with rituximab for difficult steroidresistant and -dependent nephrotic syndrome: multicentric report. Clin J Am Soc Nephrol 2010;5:2207-2212.

52 Francois H, Daugas E, Bensman A, Ronco P: Unexpected efficacy of rituximab in multirelapsing minimal change nephrotic syndrome in the adult: first case report and pathophysiological considerations. Am J Kidney Dis 2007;49:158-161.

53 Munyentwali H, Bouachi K, Audard V, Remy P, Lang P, Mojaat R, et al: Rituximab is an efficient and safe treatment in adults with steroid-dependent minimal change disease. Kidney Int 2013;83:511-516.

54 Bruchfeld A, Benedek S, Hilderman M, Medin C, Snaedal-Jonsdottir S, Korkeila M: Rituximab for minimal change disease in adults: long-term follow-up. Nephrol Dial Transplant 2013, Epub ahead of print.

55 Takei T, Itabashi M, Moriyama T, Kojima C, Shiohira S, Shimizu A, et al: Effect of singledose rituximab on steroid-dependent minimal-change nephrotic syndrome in adults. Nephrol Dial Transplant 2013;28:1225-1232.

$56 \mathrm{http}: / /$ clinicaltrials.gov/show/NCT01268033.

57 Sugiura H, Takei T, Itabashi M, Tsukada M, Moriyama T, Kojima C, et al: Effect of singledose rituximab on primary glomerular diseases. Nephron Clin Pract 2011;117:c98c105.

- 58 Javaugue V, Karras A, Glowacki F, McGregor B, Lacombe C, Goujon JM, et al: Long-term kidney disease outcomes in fibrillary glomerulonephritis: a case series of 27 patients. Am J Kidney Dis 2013;62:679-690.

59 Syeda UA, Singer NG, Magrey M: Anti-glomerular basement membrane antibody disease treated with rituximab: a case-based review. Semin Arthritis Rheum 2013;42:567-572.

60 Cuadrado MJ, Sciascia S, Bosch X, Khamashta MA, Ramos-Casals M: Is it time for biosimilars in autoimmune diseases? Autoimmun Rev 2013;12:954-957.

61 Turner-Stokes T, Sandhu E, Pepper RJ, Stolaqiewicz NE, Ashley C, Dinneen D, et al: Induction treatment of ANCA-associated vasculitis with a single dose of rituximab. Rheumatology (Oxford) 2014, Epub ahead of print. 